\title{
Experiences with radioactive gold in the treatment of craniopharyngioma
}

\author{
WILLIAM H. BOND, DAVID RICHARDS, AND ERIC TURNER \\ From the Queen Elizabeth Hospital, Birmingham
}

The treatment of choice for craniopharyngioma is still controversial and probably ought to vary in individual cases. Where the histological structure is benign a total removal has seemed an ideal to aim at. The lesion is, however, frequently adherent to the hypothalamus, to main cerebral vessels, and to the optic tracts as well as to the pituitary stalk, and attempts at total removal have resulted in a forbidding operative mortality even when the attempt was abandoned because the operation proved technically impossible. When apparently complete removal was achieved there was still a substantial recurrence rate $(35 \%)$ in the survivors (Gordy, Peet, and Kahn, 1949). In many instances histological examination showed anaplastic cell growth and mitotic figures, malignant changes which precluded any serious attempt at surgical extirpation. The lesion usually consists of one or more cysts, though about one in 10 is a solid tumour. After incomplete removal of a cyst wall and aspiration of contents in most of the surviving patients the lesion recurred in three to six months (Ingraham and Scott, 1946), although an occasional patient survived longer, even up to 13 years. Russell and Pennybacker (1961) pointed out that the course was more variable in older patients, and that there might be spontaneous remissions lasting as long as 20 years, though 10 out of 24 patients were dead within 15 months of first being seen. The cause of deterioration was probably an increase in volume of cyst contents, though there was little to show how this came about. Oedema on a vascular basis was proposed to explain the fluctuations in the clinical state arising from solid tumours. In the younger patients at least simple aspiration, decompression, and ventriculo-cisternostomy (Torkildsen's operation) afford usually only temporary relief.

Although craniopharyngioma has frequently been regarded as radio-resistant, several workers have reported a useful result from radiotherapy on a small number of cases (Love and Marshall, 1950) with periods of survival up to eight years. Ingraham and Scott (1946) advocated irradiation instead of decompression for a later recurrence. Carpenter,
Chamberlin, and Frazier (1937) in four cases aspirated the cyst and then irradiated it with doses between 1,000 and 3,500 over a long period. In their cases there was no recurrence in 17 to 30 months, whereas before irradiation the cysts required aspiration at intervals of three weeks to six months. Kramer, McKissock, and Concannon (1961) used two million volt rays by a rotation technique to irradiate the craniopharyngioma with doses of $5,500 \mathrm{r}$ over six weeks in children and of 7,000 r over seven weeks in adults. Their results were startling. Nine out of 10 patients, including six children were well after six years or more. One case had ro quired re-aspiration. None showed clinical evidence of damage to the brain due to irradiation.

Our work was started before these last results were $\mathbb{D}$ published. One aim of radiation therapy is to destrom the secretory epithelium so that a cystic cranice pharyngioma does not re-form. Consequently we. decided to use an isotope material whose effect woul $\mathscr{Q}$ be largely restricted to the cyst lining whilst having or insufficient penetrating radiation to affect nearby hypothalamic structures. One argument against this technique is that the craniopharyngioma is not always a unilocular cyst, but may consist of a number of thin-walled cysts, a complex multilocular cystic mass $\stackrel{\square}{\varnothing}$ with some solid material, or a solid mass with no $\underset{\vec{P}}{\overrightarrow{2}}$ cystic spaces at all. Nevertheless the majority of cases do have one or more large cysts which can be emptied through a single aspirating cannula, and it is feasible $\frac{F}{0}$ to treat such a lesion by local injection of radioactive material.

The choice of isotope material was not difficult, for radioactive gold $\left({ }^{198} \mathrm{Au}\right)$ in colloidal form which emits $95 \%$ of beta-radiation with $0.96 \mathrm{Mev}$ energy, and $5 \%$ of gamma radiation with $0.41 \mathrm{Mev}$ energy, would remain within the cyst cavity and is readily available. The maximum penetration of the beta 9 particles is $3.8 \mathrm{~mm}$. and the half value layer $0.3 \mathrm{~mm}$. $\frac{D}{2}$ Assuming a cyst capacity of approximately $50 \mathrm{ml}$. it appeared to a first approximation that 100 milli- $N$ curies would not exceed brain tolerance at a depth of $1.0 \mathrm{~cm}$. although the cyst lining would be re- $N$ ceiving a dose in excess of 20,000 r. This dose was $\omega$ 
felt to be high enough to cause complete destruction of the epithelial lining; a useful dose of the order of $1,000 \mathrm{r}$ beta and 5,000 $\mathrm{r}$ gamma would be received at a depth of $1.5 \mathrm{~mm}$. but at a depth of $1.0 \mathrm{~cm}$. the dose would be entirely gamma radiation and under 2,000 r. Inevitably any calculation of dosage can only be approximate for it is almost impossible to estimate with any degree of accuracy what the capacity of a cyst is, or the degree of dilution of the injected radioactive material by residual fluid left after aspiration, and there is no certainty that the material is not deposited in one small area because of failure to mix completely. On the other hand the dose to the cyst lining being delivered by the radiogold within $3.8 \mathrm{~mm}$. of the surface of the cyst is dependent on dilution, whereas the dose $1.0 \mathrm{~cm}$. deep to the cyst surface, being pure gamma, is independent of dilution of radioactive material. For these reasons it was felt safe to calculate the dose of radioactive gold to be given from the gamma ray dose delivered to $1.0 \mathrm{~cm}$. beyond the cyst lining, that is, in presumably normal neural tissue. Assuming a $4.0 \mathrm{~cm}$. diameter cyst this dose was $2,430 \mathrm{r}$ gamma when the cyst contained 100 millicuries of radioactive gold.

\section{METHOD}

At a first operation the nature of the tumour was determined by inspection and aspiration, sometimes including biopsy. In three cases removal was attempted but was followed by recurrence. At a subsequent operation the frontal flap was again elevated and the frontal lobe retracted or a burr hole was used. In either instance the cyst was punctured by a cannula. The contents were washed out by barbitage with saline so that the cyst would not be lost. After it was fairly thoroughly washed out, as judged by the pale colour of the fluid and the lack of cholesterol crystals in the aspirate, colloidal gold was inserted and mixed well with the contents. The hole in the cyst wall was closed with a small piece of gelatine sponge.

\section{CLINICAL MATERIAL}

In none of the first four cases was the radioactive gold inserted as a primary procedure. All the cysts had recurred after apparently complete extirpation in one case, and partial removal and decompression in the other three. In each of these cases the diagnosis was confirmed by histological examination.

CASE 1 A boy of 13 years was admitted in March 1959 with a history of intermittent frontal headache and vomiting for four months. Between attacks he was normal at first but for a week had noticed blurring of vision, fatigue, listlessness, and stiffness of the neck. He was found to be an intelligent child, slightly obese, with bilateral papilloedema. Radiographs of the skull showed destruction of the sella turcica, suprasellar calcification, and separation of the sutures. An electroencephalogram showed delta waves over the right hemisphere. Before the illness he had been above average intelligence, a bright grammar school boy.

Craniotomy under hypothermia revealed a cystic tumour protruding forwards beneath and above the optic chiasma. It was opened and the liquid contents, containing cholesterol crystals, were sucked out. Five weeks later at another operation under hypothermia an attempt was made to remove the cyst walls, but these were so adherent to blood vessels and the hypothalamus that removal was not completed. Post-operatively the child was stuporose with extreme hypothermia and diabetes insipidus. With cortisone, thyroid, and pituitary snuff he gradually improved. Visual acuity was $3 / 60$ on the left, $2 / 60$ on the right.

In January 1961 a routine check-up in hospital included a small pneumoencephalogram. The third ventricle was still displaced upwards and backwards, but there was no obstruction. The cyst had presumably re-formed. In July he was re-admitted because of vomiting. He was grossly dehydrated from vomiting and diabetes insipidus. After the fluid balance had been restored the intracranial cyst was tapped again and radioactive colloidal gold, 100 millicuries in $4 \mathrm{ml}$., was inserted. Post-operative progress was satisfactory. Diabetes insipidus was controlled by pituitary snuff. Visual acuity on the left had improved to $6 / 9$ and $\mathrm{J} 1$.

In October 1961 he developed a cold and a week later he was found to be unrousable. He recovered without treatment and was presumed to have had a fit. He had become obese again, and the hair had fallen out over the scalp flap. The sodium and chloride levels were low. The hormonal state was assessed and hormonal medication was increased to $50 \mathrm{mg}$. of cortisone and $0.3 \mathrm{mg}$. thyroxine daily.

In April 1962 he was admitted to hospital with right lower lobar pneumonia. He had suffered during the previous three months from attacks of unconsciousness, once with a generalized convulsion. Cortisone was reduced, and thyroxine and pitressin were stopped. Temperature varied from $102^{\circ} \mathrm{F}$ to $84^{\circ} \mathrm{F}$. On antibiotics he improved. He was eventually discharged on cortisone $150 \mathrm{mg}$., thyroxine $0.3 \mathrm{mg}$., and testosterone $10 \mathrm{mg}$., all daily. On these doses he remained fairly well. He slept only for four to six hours at night, then could not return to sleep. Twice each night he rose to pass urine. He attended school intermittently.

In December 1962 he began to have weakness of the legs. On radiographs a small area of patchy opacity was seen at the right lung base. The temperature was $94^{\circ} \mathrm{F}$. Sputum produced a heavy growth of coagulase-positive staphylococci with a moderate growth of Streptococcus viridians and monilia. He was put on tetracycline. Eleven days later he was brought into hospital in extremis and died five minutes later. At the time of death he was still obese. The height was $167 \mathrm{~cm}$., on the third percentile. The head circumference was $58 \mathrm{~cm}$. The fingers were tapering, the scalp hair had grown again but there was a very small amount of pubic hair and no axillary hair. The penis and testicles were small.

Examination at necropsy showed appearances illustrated in Figure 1. 


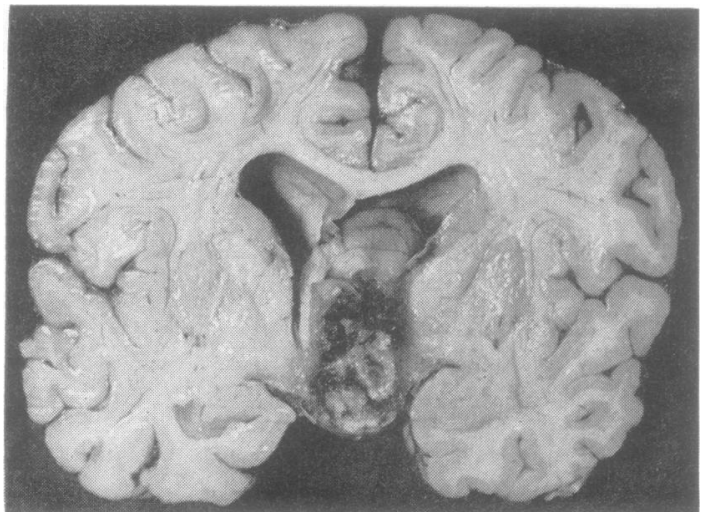

FIG. 1. Coronal section in case 1. The extension of the tumour upwards beside the foramen of Monro on the right side is clearly seen.

A mass of apparent tumour tissue covered the optic chiasma and extended upwards to replace the hypothalamus. The pituitary was smaller than normal. The thyroid was slightly smaller than average as were the adrenal glands and the testes. The lungs showed bronchopneumonia from which grew a heavy growth of coagulasepositive staphylococci insensitive to antibiotics. Histology of the pituitary gland showed no necrosis, fibrosis, or degeneration in either lobe. The anterior lobe had an increase of eosinophil and basophil cells and a reduction in chromophobes. The basophils often showed a pale eccentric paranuclear zone devoid of stainable granular material. The posterior lobe was unremarkable. Thyroid showed inactive glandular tissue with uniformly thinwalled vesicles distended with colloid. The testes had a normal prepubertal appearance of the seminiferous tubules with germinal cells normal in number, but no evidence of spermatogenesis. The interstitial connective tissue septa were thickened but there was no proliferation of Leydig cells.

The craniopharyngioma itself showed no remaining viable elements (Figs. 2, 3). It consisted largely of necrotic tumour cells embedded in a fibrin net meshwork containing cholesterol clefts. The central part consisted of vascular granulation tissue which extended into the necrotic tumour at the margin of the mass. It was partly enclosed by a thick acellular fibrous capsule. Small processes of necrotic tumour extended through the capsule into surrounding brain tissue. They were sometimes calcified and commonly invested by foreign body giant cells. Several showed a resemblance to the benign calcifying epithelioma of Malherbe with retention of cell outlines in the necrotic epithelium. Gold was seen as black isotropic granules which were negative to the Prussian blue reaction and dissolved in potassium cyanide. The bulk of it was retained within the tumour, some being retained in the wall. A small amount lay within the immediately surrounding glial tissue. The granules were gathered in clumps indicating that they were mainly intracellular. In addition there was a moderate amount of haemosiderin pigment round the margins of the tumour.

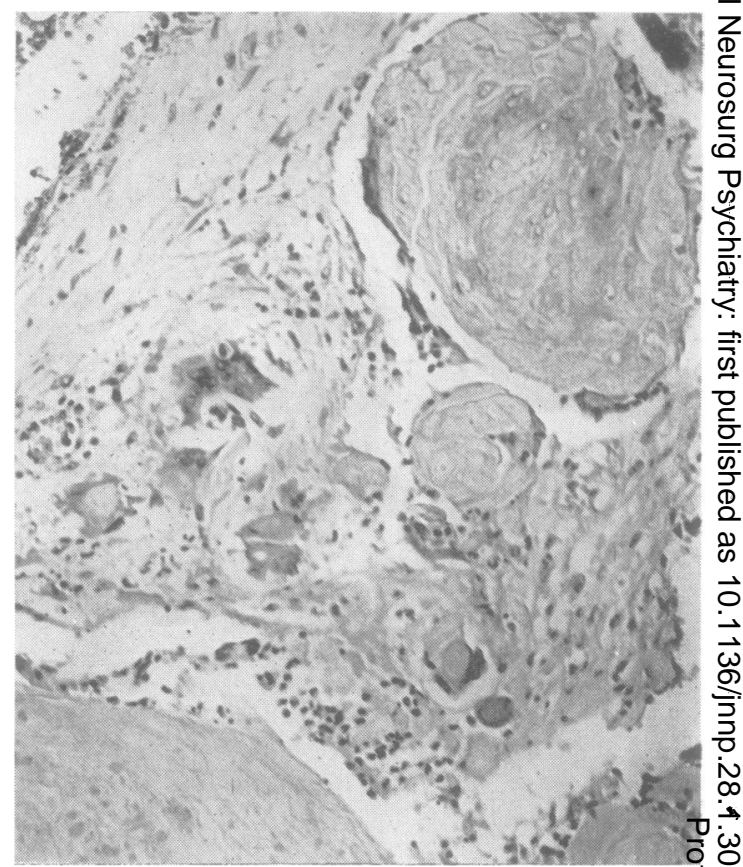

FIG. 2. Section from the edge of the tumour (case $\bar{g}$ ) 응 showing necrotic islands of epithelial tumour with related multinucleated foreign body giant cells. Haematoxylin 7 and eosin $\times 193$.

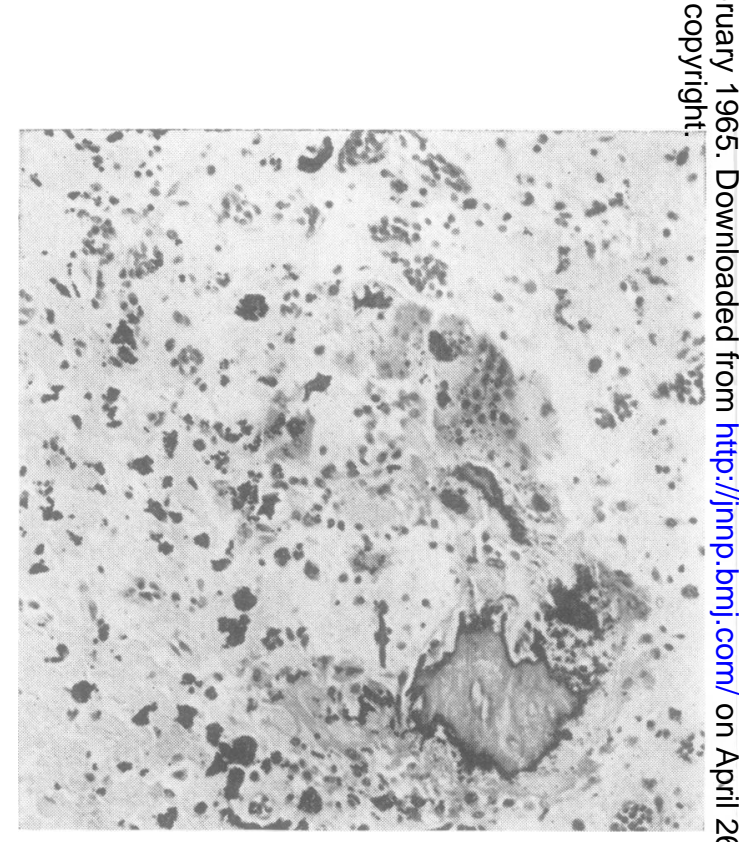

FIG. 3. Centre of tumour (case 1) showing partly calcified necrotic tumour with giant cells. The aggregates of black $\mathrm{D}$ granules are gold. Haematoxylin and eosin $\times 193$. 
The surrounding brain tissue, including the medial nuclei of the thalamus, on both sides showed extensive fibrous gliosis and demyelination. This was associated with eosinophilic swelling of glial cells. Nerve cells of the medial thalamus were reduced in number and those remaining were completely degenerate consisting of barely recognizable pale ghost cells. Although there was focal haemorrhage into the tumour no vascular lesions were seen either here or in surrounding brain tissue.

In his conclusion to this report Dr. A. Hugh Cameron stated that in his view the appearances were that the irradiation from the colloidal gold had caused complete necrosis of the tumour and also severe degeneration of surrounding tissue. Death was due to staphylococcal tracheo-bronchitis.

CASE 2 A coloured Jamaican boy of 12 years was admitted in November 1958 with seven weeks' history of vomiting and weakness of the left face, arm, and leg. He was found to have papilloedema of the right eye, visual acuity being $6 / 18$ on the right, normal on the left. A right carotid angiogram showed upward displacement of the carotid bifurcation with straightening of the syphon and elevation of the middle cerebral artery and also of the central veins. Through a right frontal craniotomy a large suprasellar cyst, extending laterally into the right Sylvian fissure, was tapped.

In January 1959 the craniotomy was reopened under hypothermia. The cyst wall was stripped in fairly large portions from the optic nerves, the hypothalamus, pituitary stalk, and right optic tract. Following the operation the child had a left homonymous hemianopia but otherwise was remarkably well, showing hardly any reaction to the procedure. A complete macroscopic removal had been performed. Histological examination of the wall showed large epithelial nests surrounded by cellular collaginous tissue. The epithelium had a mixed keratinizing and adamantinomatous appearance, and there were areas of cholesterol granuloma. Although the tumour was not frankly malignant local invasion and post-operative recurrence were anticipated in the report of Dr. A. H. Cameron.

In July 1959 he was re-admitted and a large recurrent cyst was aspirated of $120 \mathrm{ml}$. of fluid containing cholesterol crystals. In the subsequent months he developed a progressive left spastic hemiparesis. In September 1961 the cyst was tapped through a burr hole, and 100 millicuries of radioactive colloidal gold in $3 \mathrm{ml}$. was introduced and mixed with the cyst contents.

He improved to some extent after this operation, but in February 1962 he was re-admitted because of excessive drowsiness which had increased over a week until he was roused only with difficulty, and spoke only with extreme persuasion. Bilateral carotid angiograms were normal. The E.E.G. showed bilateral frontal slowing. The cyst was re-aspirated but only $15 \mathrm{ml}$. of cerebrospinal fluid was obtained. A ventriculogram showed slight tilting of the lower end of the third ventricle towards the left, but otherwise was normal. The pressure was normal.

His mental state remained abnormal. He was inco- operative and persistently incontinent. He dribbled saliva and speech was slurred. Under treatment with thyroxine. $0.1 \mathrm{mg}$. b.d., prednisolone $7.5 \mathrm{mg}$. b.d., and phenobartitone, he improved slightly, but remained lethargic. In May 1963 he died in another hospital. No necropsy was performed.

CASE 3 A married housewife aged 51 years had been in hospital in March 1960 with a history of gain in weight, lassitude, and lethargy which was diagnosed as myxoedema because of a blood cholesterol level of $360 \mathrm{mg} . \%$, and a B.M.R. of $-10 \%$. She was re-admitted in July 1960 . During the previous day she had suffered from repeated generalized fits. Examination revealed bilateral papilloedema and a left ptosis with unequal pupils, the right larger than the left. There were no other abnormal neurological signs. Cerebrospinal fluid protein was 112 $\mathrm{mg}$. per $100 \mathrm{ml}$. A left carotid angiogram raised suspicion of ventricular enlargement, a vertebral angiogram failed, and ventriculography was not done. Since her blood pressure was raised to $240 / 120 \mathrm{~mm}$. $\mathrm{Hg}$ her condition was diagnosed as hypertensive encephalopathy. She was re-admitted in March 1961 with ataxia and lack of concentration, going on to confusion then stupor. An E.E.G. revealed slow waves more prominent frontally. An air and Myodil ventriculogram revealed a block at the foramen of Monro.

Frontal craniotomy showed a cyst containing cholesterol crystals protruding from the right wall of the third ventricle in the normal position of the hypothalamus and extending backwards towards the thalamus and laterally behind the head of the caudate nucleus on the right side.

Histological examination showed the wall to be composed of epidermis with calcification and with no evidence of malignancy. After this operation she improved considerably for a time but in February 1962 the cyst had recurred. It was re-aspirated and washed out and 50 millicuries of colloidal radioactive gold in $4 \mathrm{ml}$. injected. She recovered consciousness quickly but next day developed signs of acute coryza. Her conscious level deteriorated and four days after operation she became comatose with Cheyne Stokes respiration. The cyst was again re-aspirated, $10 \mathrm{ml}$. fluid being obtained containing the radioactive gold. Sixty per cent of the radioactivity had already been emitted. Within 24 hours she had improved again and was answering questions lucidly. She was discharged on $50 \mathrm{mg}$. of cortisone daily and thyroxine $0 \cdot 1 \mathrm{mg}$. daily.

During the next nine months she was noted to react violently to intercurrent infections such as a sore throat. At such times she became confused and even stuporose. She died at home in November 1962 and through the kindness of Dr. Bence a post-mortem examination limited to the brain was obtained (Fig. 4).

The anterior limit of the tumour was just behind the optic chiasma separating the two optic tracts and here was a mass of haemorrhagic tissue with a solid nodule behind it $2 \mathrm{~cm}$. vertically by $1 \mathrm{~cm}$. laterally. There was a large area of old softening on the right side bordering on the dorso-lateral angle of the right lateral ventricle just dorsal to the caudate nucleus extending from the ependyma to the cortical surface. 


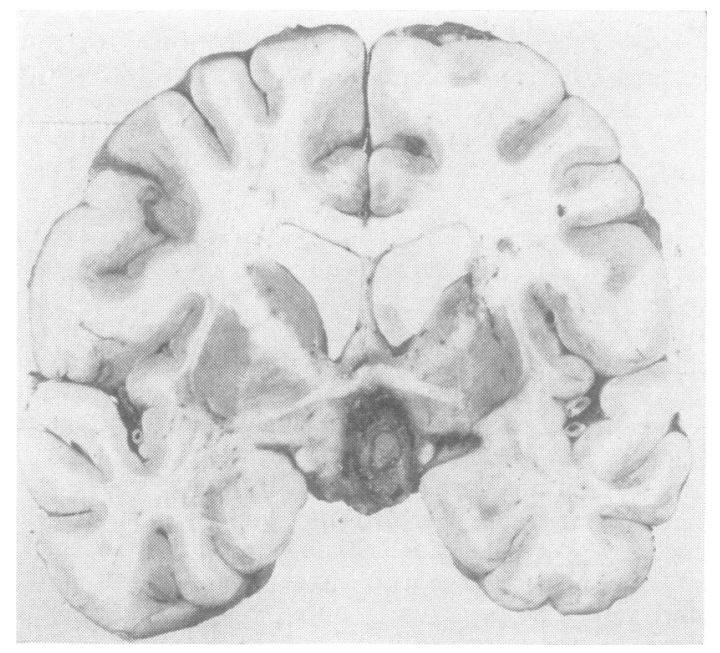

FIG. 4. Coronal section through tumour at its maximum extent in case 3.

Histology showed necrosis of the tumour with some material resembling keratin recognizable in a few areas, and sometimes infiltrating surrounding cerebral tissues. Some foci showed giant foreign body cell reaction. A collagenous capsule surrounded the tumour incompletely. The cerebral arteries showed fibro-fatty intimal thickening, elastosis, medial degeneration, and fibrosis. Some branches of the middle cerebral artery showed fibrous occlusion with some evidence of recanalization. The optic tracts showed demyelination and gliosis and the floor of the third ventricle was eroded and gliotic. The medial thalamic nucleus showed gross loss of neurones, astrocyctic hyperplasia, and perivascular infiltration with chronic inflammatory cells. The white matter of the centrum semiovale and internal capsule showed microcystic degeneration and focal lipophage aggregates. Many phagocytes around the tumour contained unidentified black granules thought to be radioactive gold. The mamillary bodies were destroyed. There appeared to be fresh bleeding in the posterior part of the tumour mass.

In Dr. W. T. Smith's opinion the large area of softening was an old lesion consistent with healed infarction. Blood vessels in the vicinity showed fibrous gliosis. Throughout the cortex of the hemisphere were macroscopic foci of old gliosis and recent spongiform degeneration consistent with local ischaemia. The Sommer sector was similarly affected. The pituitary gland showed atrophy. He commented that the lesions of the adjacent brain and blood vessels were probably attributable in part to local radiation.

CASE 4 A boy aged 5 years was admitted in July 1956 with a history of change of personality three months previously when he began to be restless, then careless and dirty. His concentration deteriorated, where he had before $\underset{\mathbb{Z}}{Z}$ been interested and intelligent. He ceased to be affection- $\frac{\Gamma}{\bar{D}}$ ate. For the last month he had developed headaches and $\%$ vomiting. On examination he was drowsy and unsteady in gait with a left spastic hemiparesis, increased reflexes in all four limbs, enlargement of the right pupil, and biphasic plantar responses. Investigation by ventriculo- $\frac{\widehat{\Upsilon}}{\partial}$ gram showed a large suprasellar mass protruding into $\overline{0}$. the third ventricle. Right frontal craniotomy was per- $\stackrel{2}{2}$ formed and $30 \mathrm{ml}$. of yellow fluid containing cholesterol crystals was aspirated from a suprasellar cyst. The cyst $\overrightarrow{\bar{F}}$ wall was separated from the hypothalamus and was apparently completely removed.

Histology of the wall showed squamous epithelium on $\frac{\bar{\sigma}}{\bar{S}}$ fibrous tissue with some areas of lipogranulomatous $\frac{\sigma}{7}$

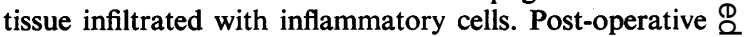
progress was uneventful and he was discharged on thyroid $30 \mathrm{mg}$. b.d.

Subsequently his progress was unsatisfactory. The $\overrightarrow{0}$ hemiparesis cleared up but he became more obese, and $\overrightarrow{\vec{H}}$ more emotionally labile and uncooperative until he $\vec{\omega}$ even stopped attending a school for subnormal children. In May a recurrent cyst was aspirated of $35 \mathrm{ml}$. of dark yellow fluid containing cholesterol crystals and $5 \mathrm{ml}$.

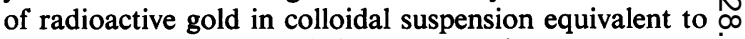
115 millicuries was instilled. Post-operative progress was $\overrightarrow{.}$ uneventful and he was discharged from hospital nine day later.

Subsequently he continued to be moderately obese्f irritable, naughty, hyperkinetic, distractable, and a胥 7 parently unable to learn any school subject, though 退 could memorize tunes. After a period of a few months of progressive physical deterioration with spastic quadro ฏ paresis and drowsiness amounting at times to stupor, developed pneumonia and died on 11 September $1963 \frac{0}{5} \overrightarrow{0}$

At necropsy there was a general appearance of $\vec{a} \mathrm{or}$ Fröhlich's syndrome. Examination of the brain revealed a thin-walled cyst $3 \mathrm{~cm}$. in diameter occupying the suprasellar position. The pituitary gland was attached to the under surface of the cyst and had a necrotic brownish $\overline{\bar{O}}$ yellow appearance, the upper part apparently containing an extension of the cyst. Alongside the main cyst in the left Sylvian fissure was a cyst cavity $1 \frac{1}{2} \mathrm{~cm}$. in diameter $\underset{\vec{B}}{\vec{B}}$ with a shiny, silvery blue coloured wall apparently $\frac{\bar{O}}{3}$ invading the overlying globus pallidus and internal capsule (Fig. 5). The postero-medial part of the right lateral ventricle showed several smooth greyish nodules? arising from the ependymal lining and protruding into the lumen. On section these consisted of well-demarcated ectopic cortical tissue. The upper part of the aqueduct was slightly dilated and there was coning of the cerebellar 3 tonsils through the foramen magnum. The foramina of Monro on both sides were partly occluded more particularly on the left side.

Histological examination showed that the cyst wall 을 consisted of squamous epithelium with a varying amount $D$ of stratification. In the thicker parts the basal layer was cuboidal and occasionally there was reticular formation similar to that in adamantinoma. There were some nodules $\sigma$ of ghost-like and sometimes calcified squames on the $\mathrm{N}$ inner aspect. In none of the numerous sections examined $\mathrm{N}$ was there penetration of epithelial elements into the $\frac{\omega}{\sigma}$ 


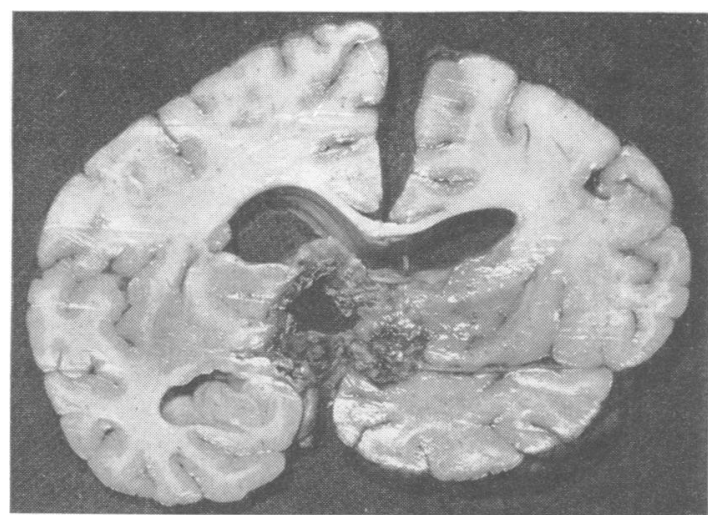

FIG. 5. Coronal section of the brain of case 4 at the maximum diameter of the tumour. The small cyst in the left Sylvian fissure contains gold.

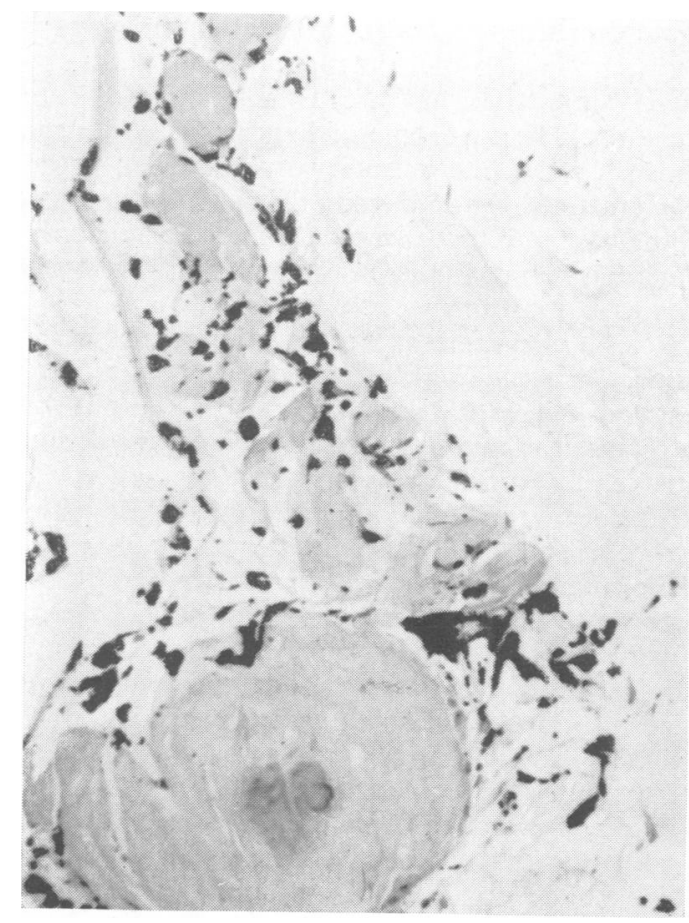

FIG. 6. In case 4 the cyst wall in the left Sylvian fissure shows necrotic, partly calcified, epithelial remnants, black gold pigment, and pale hyaline fibrous cyst wall. Haematoxylin and eosin $\times 193$.

surrounding parenchyma, and loose, moderately vascular connective tissue intervened between the two.

The anterior pituitary was expanded and partly replaced by two rounded foci consisting largely of necrotic tissue with cholesterol clefts and multinucleated giant cells. These lesions were associated with intracellular haemosiderin around the margins and did not contain recognizable tumour elements. The larger had a fibrous wall and both were in close contact with the cyst wall posteriorly.

The cyst within the left Sylvian fissure had a thick wall of hyaline collagen. It contained necrotic debris with cholesterol clefts and much gold pigment which appeared black in sections stained with haemotoxylin and eosin. On the inner surface of the fibrous wall and also embedded within its substance were syncytial masses of necrotic ghost-like squames, many of them calcified. Multinucleated giant cells were also encountered in this zone but no viable tumour tissue. In places the fibrous wall was thin or incomplete and here much gold pigment was seen in the surrounding connective tissue (Fig. 6). Several large branches of the left middle cerebral artery showed marked hyaline thickening of the elastic lamina and much fibrous thickening of the intima. In one the lumen was almost completely obliterated and the appearances suggested organized thrombus. The surrounding brain tissue had a loose spongy texture and contained swollen astrocytes and microglia with relatively little fibrous gliosis. This zone often contained intracellular haemosiderin. The optic tract on the left side showed complete demyelination. The zone of degeneration around the cyst was narrow and intact healthy nuclear tissue was seen within $1 \mathrm{~mm}$. of dense gold deposits in the left Sylvian fissure.

The remainder of the sections was unremarkable. There was a moderate amount of granular ependymitis in the lateral ventricle. The heterotopic grey matter lining the ventricles consisted of healthy neurones showing laminar organization.

Dr. Hugh Cameron thought that much of the degeneration of surrounding brain tissue appeared to be secondary to vascular involvement and the lesions in the anterior lobe of the pituitary to be due to haemorrhage around the margin of the cyst wall. The craniopharyngioma was for the most part viable but only the extension within the left Sylvian fissure contained gold. In this part there were necrotic epithelial elements and no viable tumour. The gold here appeared to have leaked outside the cyst wall. The severe obliterative arterial lesions were probably related to the instillation of radioactive gold. 'Heterotopic grey matter in the wall of the lateral ventricles is commonly found in malformations of the brain but I am not aware of its being associated with craniopharyngioma'.

CASE 5 A Sikh boy of 13 years entered hospital in November 1962. At the age of 5 he had developed severe frontal headache with vomiting, and next day the vision in the left eye was found to be impaired. Vision deteriorated further until he was blind in the left eye, with gross impairment of vision in the right eye. He continued to have headaches, and for two years or so had experienced excessive thirst and polyuria. He was found to be a bright, intelligent boy, who spoke little English, but com- 
municated freely through an interpreter. He was undersized with no sexual development. There was a divergent strabismus. The left eye had only perception of light in the nasal half field; the right eye had a complete temporal hemianopia, with intact nasal field. Both optic disks showed primary atrophy. Neurological examination otherwise was normal. $X$-ray examination revealed calcification above the sella. A left carotid angiogram showed elevation of the anterior cerebral artery with displacement of it from left to right across the midline. In December a left frontal craniotomy was performed. A large cyst containing over $150 \mathrm{ml}$. of clear yellow fluid was found inside the frontal lobe and extending under the falx to the other side. In addition, a separate cystic craniopharyngioma with brown fluid contents and cholesterol crystals was discovered above the sella between the optic nerves. Both cysts were aspirated, that in the frontal lobe was filled with air, and $0.5 \mathrm{ml}$. Steripaque was inserted in the craniopharyngioma. Radiographs afterwards showed the intracerebral cyst to be the loculated dilated anterior horn of the ventricle. The Steripaque could not be identified in distinction to the calcified wall of the cyst. In January 1963 at a second craniotomy the craniopharyngioma was tapped and $\mathbf{2 0}$ millicuries of radioactive gold was inserted. The ventricle was opened, and the obstruction was found to be due to another large loculus of the cyst which was aspirated. The wall between it and the inferior loculus was broken down until the purple gold suspension flowed freely between both compartments. Biopsy was taken from the cyst in the frontal lobe, and this showed only ependyma, confirming that this represented a loculated frontal horn.

Post-operative progress was uneventful. Vision was unchanged in the immediate post-operative period. $\mathrm{He}$ was treated with cortisone and with pituitary snuff, which did not, however, seem to influence moderate diabetes insipidus to any significant degree. When last seen in May 1964 he was attending school and was able to read with the right eye, the left being blind. He had grown an inch in three months, but had lost weight.

\section{RESULTS}

The first four cases were treated by surgical methods but the lesions recurred in periods ranging from six months to three years and eight months. They were then treated by insertion of radioactive colloidal gold. One of the patients was a hypertensive woman of 51 years who died nine months after use of radioactive gold which had been removed four days after insertion. At necropsy no viable tumour was seen. Destruction of the hypothalamus surrounded the cyst wall, and was accompanied by patches of destruction elsewhere in the brain. The patient showed diminished resistance to ordinary respiratory infections in spite of hormonal replacements. All the other patients were children. One died a year and a half after insertion of the gold and again the tumour was completely destroyed while hypothalamic tissue was destroyed or damaged round it. The child had suffered from pneumonia without pyrexia. One other child died in another hospital. No post-mortem examination was performed. All these children had on doses in the region of 100 millicuries. A fourth case had a bilocular cyst, only one loculus being treated $D$ with the gold. At death the other loculus was still viable. A fifth case has been treated in the first instance with radioactive gold, in a more conservative dosage of 20 millicuries. The follow-up is now 15 months.

\section{DISCUSSION}

This series demonstrates that it is possible to destroy a craniopharyngioma completely by the injection of radioactive gold in colloid form. Whilst compression may have played a part in damaging the surrounding hypothalamus, in review it appears to be certain that excessive radiation played the most important part in causing damage. The question remains unsolved whether the tumour can be utterly destroyed without lasting harm to surrounding neural structures. The syndrome of hypothalamic destruction as opposed to pituitary hypofunction is not clearly defined, but Jefferson (1957) suggested tha hypothalamic disturbances were the probable cause of mental changes in these cases, and our histologica findings support this view.

If craniopharyngioma can be safely destroyed byo radioactive gold it will be important to institute thiso treatment before the condition is so advanced that the disease has caused irreversible damage. The four? patients in whom the outcome has already been unsatisfactory were all in coma from the disease before treatment, and some had been in coma several times.

The alternative treatment by external radiation differs from local irradiation in two respects. External radiation cannot be restricted entirely to the cyst and inevitably irradiates considerable volumes of adjacent brain; neither can it display the extremely rapid fall off in dosage of beta radiation to confine treatment to a few millimetres only. The intracystic injection of radioactive material allows the pattern of radiation to conform to the shape of the cyst, provided the total dose to the adjacent neural tissue can be kept to safe levels. The continued satisfactory progress without neurological change in the case receiving only 20 millicuries of radioactive gold suggests that the method may be safe and effective at lower dosage levels. It is abundantly clear that a dose of 100 millicuries irrespective of the size of the cyst damages the hypothalamus far in excess of tolerance. Case 3, in which the material was aspirated four days after injection, received a radiation dose equivalent to approximately 30 millicuries: but even so cerebral deterioration occurred 
within a few weeks and death within nine months, and at necropsy destruction of a long-standing cyst was apparently complete. It is probable that radiation played a smaller part in brain damage in this case but the local reaction from the initial 50 millicuries of radio-gold proved more than pressuredamaged neural tissue adjacent to the cyst could tolerate. Experience with radioactive colloidal gold at other sites suggests a possible explanation of the high dose effects noted in this series in that a specimen of pleural effusion or ascitic fluid taken three days after injection of $\mathbf{3 0 0}$ millicuries shows an unexpectedly low level of radioactivity, and we now believe that the colloidal nature of the radioactive gold is lost soon after injection. The material lost from suspension accumulates evenly or unevenly on the lining. Such a change will have no effect on the gamma dose at a depth of more than $3.8 \mathrm{~mm}$. but will markedly increase the beta radiation dose within this distance, especially should the material accumulate in an irregular fashion. Even so it is difficult to explain brain injury at a depth of more than $0.5 \mathrm{~cm}$. from the lining of a $4.0 \mathrm{~cm}$. cyst as a pure effect of radiation, for beyond this point the neural tissue receives a dose far lower than that given by Kramer et al. (1961) even when allowance is made for the difference in overall time of treatment.

Accepting then that the gamma dose is well within the tolerance of neural tissue in the vicinity of a cystic craniopharyngioma, and that the beta dose is confined to a maximum depth of $3.8 \mathrm{~mm}$., some other explanation of the more remote damage must be sought. The intense beta radiation of the cyst lining must cause rapid necrosis of cells, an effect which would extend into adjacent normal neural tissue if necrotic weaknesses in the cyst lining permitted the escape of radioactive material as judged by postmortem appearances in cases 1 and 4 . The presence of necrotic brain tissue might promote an aseptic inflammatory process in the adjacent hypothalamus resulting in the fibrous gliosis and demyelinization described at necropsy. In case 3, however, not only were these changes marked in the vicinity of the cyst in the hypothalamus, but they were also noted as patches of destruction elsewhere in the brain. This patient was hypertensive, but in view of the latter finding it is possible that the presence of necrotic brain tissue initiated an auto-immune response in more distant parts of the brain, with resulting demyelination and gliosis. Such a view is supported by the disproportionate severity of the histological changes when related to the radiation dose given, the absence of any vascular changes such as are seen in radiation overdosage of brain, and by the rapid appearance of mental changes in two cases within a period of weeks as opposed to the usual intervals of many months when this region of the brain is damaged by radiation.

Since vascular insufficiency has been found by Asscher and Anson (1962) to render brain tissue more vulnerable to the effects of irradiation, this represents another factor which may predispose these patients to suffer disproportionate changes in areas affected by the ischaemia of either compression or hypertension.

There is one further reservation about the method in that the cystic mass may be multiocular. It can be determined by aspiration whether the main cyst has been tapped and tiny separate loculi will be dealt with by the radiation. A sizeable secondary cyst might cause recurrence, however, and in our series such a secondary cyst has occurred in the same situation in three of the cases, viz., above the main cyst, veering to one side of the midline, protruding from the floor of the anterior horn of the lateral ventricle in proximity to the foramen of Monro which may be obstructed by it. It would seem to be worthwhile to pay particular attention to this area in the ventriculogram and at operation. If the cyst protrudes into the lateral ventricle a cannula should be passed separately into this part of the cyst, if necessary by opening the ventricle. By this means it can be determined if the characteristic purple fluid of the colloidal gold is retrievable. If not further gold should be inserted, or the wall between it and the main cyst should be broken down to allow the radioactive suspension to flow into the second cyst.

\section{SUMMARY AND CONCLUSIONS}

The instillation of radioactive gold has been used in the treatment of five cases of craniopharyngioma, and when subsequently available the tumours have been carefully studied at post-mortem examination.

Evidence has been presented which indicates that the instillation of a dosage of 50 to 100 millicuries may damage brain tissue as well as destroying the cyst wall, and it is concluded that this dosage is excessive. If local instillation is used in future it is recommended that the dosage should be confined to something in the region of 10 to 15 millicuries. Before local treatment is undertaken, however, careful consideration should be given to the excellent results reported by Kramer et al. (1961), using external radiotherapy. There may yet be a useful place for the method of local instillation where the tumour consists of one or more large cysts which are accessible. Such a method could conceivably be combined with external irradiation or be followed by such irradiation in the event of deterioration subsequently. So far such suggestions of a combined 
attack are conjectural as they have not been put to the test.

We are grateful to various clinicians of the United Birmingham Hospitals for referring cases, to Dr. W. T. Smith and Dr. A. H. Cameron for pathology reports, and to Professor D. V. Hubble and Dr. R. Bence for their invaluable help in arranging for post-mortem examinations in two of the cases.

\section{REFERENCES}

Asscher, A. W., and Anson, S. G. (1962). Arterial hypertension and irradiation damage to the nervous system. Lancet, 2, 1343-1346.
Carpenter, R. C., Chamberlin, G. W., and Frazier, C. H. (1937), The treatment of hypophyseal stalk tumors by evacuation and irradiation. Amer. J. Roentgenol., 38, 162-177.

Gordy, P. D., Peet, M. M., and Kahn, E. A. (1949). The surgery of the craniopharyngiomas. J. Neurosurg., 6, 503-517.

Ingraham, F. D., and Scott, H. W. (1946). Craniopharyngiomas in children. J. Pediat., 29, 95-116.

Jefferson, A. (1957). Manifestations of suprarenal insufficiency occurring with pituitary tumours. J. Neurol. Neurosurg. Psychiat., 20, 265-275.

Kramer, S., McKissock, W., and Concannon, J. P. (1961). Craniopharyngiomas. Treatment by combined surgery and radiation therapy. J. Neurosurg., 18, 217-226.

Love, J. G., and Marshall, T. M. (1950). Craniopharyngiomas (pituitary adamantinomas). Surg. Gynec. Obstet., 90, 591-601.

Russell, R. W. R., and Pennybacker, J. B. (1961). Craniopharyngioma in the elderly. J. Neurol. Neurosurg. Psychiat., 24, 1-13. 